\title{
Hybrid waterborne polyurethane/acrylate dispersion synthesized with bisphenol A-glicidylmethacrylate (Bis-GMA) grafting agent
}

\author{
Gustavo A. Alvarez ${ }^{\mathrm{a}}$, Mónica Fuensanta ${ }^{\mathrm{b}}$, Víctor H. Orozco ${ }^{\mathrm{a}}$, Luis F. Giraldo a, *, José Miguel Martín-Martínez ${ }^{\mathrm{b}}$ \\ a Laboratorio de Investigación en Polímeros, Instituto de Química, Universidad de Antioquia, 050010 Medellín, Colombia \\ ${ }^{\mathrm{b}}$ Adhesion and Adhesives Laboratory, University of Alicante, 03080 Alicante, Spain
}

\section{A R T I C L E I N F O}

Keywords:

Waterborne dispersions

Polyurethane-acrylate

Bisphenol-A-glycidyl methacrylate (Bis-GMA)

Coatings

\begin{abstract}
A B S T R A C T
New hybrid waterborne polyurethane/acrylate (WPUA) dispersions were synthesized by grafting with bisphenol-A-glycidyl dimethacrylate (Bis-GMA) in order to create chemical bonds between polyurethane and polyacrylate chains. WPUAs were prepared by using prepolymer self-emulsifying method with isophorone diisocianate, poly(tetramethylene ether) glycol, dimethylolpropionic acid, and ethylenediamine in the polyurethanic part, and styrene and $n$-butyl acrylate in the polyacrylate portion. A redox pair system consisting of ascorbic acid and hydrogen peroxide were used as polymerization initiator. The particle size of the WPUA dispersions increased by increasing the Bis-GMA/1,4 butanediol ratio, stable dispersions of negatively charged particles were obtained, and they had low viscosity (around $1.3 \mathrm{mPa} . \mathrm{s}$ ) in spite of the relatively high solids content (27 wt $\%$ ). Higher thermal stability was obtained when $50 \mathrm{~mol} \%$ of chain extension was carried out with Bis-GMA. Using Bis-GMA/BD, instead of HEMA, as grafting agent, allowed obtaining hybrid polyurethane dispersions with the lowest mean particle size and better colloidal stability. Finally, the addition of $35 \mathrm{wt} \%$ Bis-GMA increased noticeably the cross-cut adhesion of polyurethane/acrylate coatings to stainless steel.
\end{abstract}

\section{Introduction}

Waterborne polyurethane dispersions have emerged as an important alternative respect to solvent-borne adhesives and coatings, because of the environmental problems due to the release of VOCs to the atmosphere. Since 1960s, the patent activity in waterborne polyurethane dispersions has been noticeably increased, as well as more interest in academia on the synthesis, thermal, adhesion and mechanical properties of waterborne polyurethane dispersions [1-3]. In order to improve some properties of polyurethanes obtained from dispersions such as hardness, tensile strength, elongation at break, and solvent and alkali resistance, hybrid physical blends of polyurethane and acrylic or vinyl polymers have been proposed [4,5], interpenetrated networks, hybrids prepared by end-capping [6], and grafting or crosslinking [4,7] of acrylic or vinyl monomers with polyurethane prepolymers. The particularity of the hybrid systems is the presence (grafting or end-capping) or not (physical blends and interpenetrated networks) of anchoring points into the polymer structure.
In grafting and end-capping systems, the double $\mathrm{C}=\mathrm{C}$ bond acts as anchoring sites that can be located in different parts of the polymer structure. For end-capped polymers, hydroxyethyl acrylate (HEA) [8,9] and hydroxyethyl methacrylate (HEMA) [10-12] are the most common monomers used for synthesizing hybrid polymers. The anchoring points for the hybrid formation are the ends of the polyurethane macromolecule [12] and different kinds of chemical bonds can be obtained, such as dangling chains, polyurethane pendant chains [13], and free polyurethane chains [12]. On the other hand, when the anchoring points are distributed along the backbone of the polyurethane chain, a grafting-like topology can be obtained, facilitating hybridization and crosslinking. This strategy has been less explored in the existing literature. It has been reported the use of unsaturated amine [2-(dimethylamino) ethyl methacrylate] [14] to neutralize the dimethylol butanoic acid (DMBA) moieties and at the same time to incorporate reactive double $\mathrm{C}=\mathrm{C}$ bonds into the polymer structure; these double $\mathrm{C}=$ $\mathrm{C}$ bonds were polymerized in presence of methyl methacrylate by using potassium persulfate (KPS) or azobisisobutyronitrile (AIBN) as initiators, leading to the formation of core-shell particles of polyuretane/

\footnotetext{
* Corresponding author.

Email address: luis.giraldo2@udea.edu.co (L.F. Giraldo)
} 
acrylate hybrid polymer. These hybrid polymers were more hydrophobic than the polyurethane ones.

The polymerization methodology to obtain hybrid systems is essential for obtaining adequate mechanical, chemical and adhesion properties. Most of the reported methodologies involved the emulsion $[7,8,15,16]$ and miniemulsion $[12,15,17,18]$ polymerization. However, these methodologies have some disadvantages associated to the use of solvents (for decreasing the viscosity) and the addition of external emulsifiers (for stabilizing the dispersions). Some studies avoiding the use of external emulsifiers have been published $[6,19,20]$. Xin et al. reported the so-called solvent/emulsifier free method [21] in which the polyurethane prepolymer is dissolved in vinyl and acrylic fluorinated monomers before dispersing in water. The waterborne polyurethane chains can act as dispersing agent which also help to stabilize the aqueous dispersion. In this sense by avoiding the use of solvents the preparation of "green systems" is favored, and by avoiding the use of external emulsifiers improved properties can be obtained. However, the solvent/ emulsifier free method has been used only for developing antifouling coatings and the monomers used are environmentally hazardous.

Most of the above described methods of polymerization are based on conventional radical polymerization mechanism. However, the living radical polymerization of polyurethane/acrylate copolymers, e.g. reversible addition - fragmentation chain-transfer polymerization (RAFT) [22] and atom transfer radical polymerization (ATRP) [23], has been proposed. These polymerizations are adequate when tailored macromolecular structures are required. However, they are more difficult of scaling up.

Regarding to the radical initiator system, the use of redox initiator [24] is appropriate as high temperatures are avoided, limiting the destabilization of the colloidal system. In fact, it has been reported that the ascorbic acid/hydrogen peroxide pair allow stable polyurethane/acrylate hybrid particles [17].

In this work, an alternative approach to the auto-emulsifying method is proposed to obtain waterborne polyurethane/acrylate hybrid dispersions made by grafting with bisphenol-A-glycidyl dimethacrylate (Bis-GMA) as anchoring molecule into the polyurethane macrostructure. A redox initiation system of ascorbic acid and hydrogen peroxide is used to promote the hybridization among the urethane and the acrylate chains. In order to leave unreacted terminal NCO groups, the $\mathrm{NCO} / \mathrm{OH}$ molar ratio was set to 1.30 , and the chain extension was produced in two different ways: (i) Half of the unreacted terminal NCO groups was reacted with mixture of Bis-GMA/1,4 butanediol (BD) in different molar ratios, and the other half of NCO groups were reacted with an aqueous solution of ethylenediamine (EDA); (ii) Use of hydroxyethyl methacrylate (HEMA) as end-capping agent instead of Bis-GMA/BD. The mass ratio of polyurethane/acrylate was fixed at $60 / 40$ with the acrylic part containing 50/50 styrene/n-butyl acrylate.

\section{Experimental}

\subsection{Materials}

Isophorone diisocianate (purity: 99.5\%) (IPDI) (Versanat supplied by Evonik, Essen, Germany) and poly(tetramethylene oxide) of molecular weight $2000 \mathrm{~g} / \mathrm{mol}$ (PTMO), were dried for two hours at $110^{\circ} \mathrm{C}$ in vacuum; triethyl amine (purity: 99\%) (TEA), 1,4 butanediol 99\% (BD), 1-methyl-2-pyrrolidone (purity: 99.5\%) (NMP), bisphenol-A-glycidyl dimethacrylate (Bis-GMA), ethylenediamine (purity: 99.5\%) (EDA), $n$-butyl acrylate (purity: 99\%) (BA), styrene (purity: 99\%) (ST), and 2-hydroxyethyl methacrylate (purity: 99\%) (HEMA) were purchased from Sigma-Aldrich (Sigma-Aldrich, Missouri, USA) and they were used as received. Dibutyltin dilaurate catalyst (purity: 95\%) (DBTDL) (Sigma-Aldrich, Missouri, USA) was dissolved in xylene $(10 \mathrm{wt} \%)$.

Dimethylo- propionic acid (purity: 95\%) (DMPA, Geo Specialty Chemicals, Indiana, USA) was used as internal emulsifier. L-ascorbic acid (AA) (purity: 99\%) and hydrogen peroxide $\left(\mathrm{H}_{2} \mathrm{O}_{2}\right)$ with $35 \%$ concentration, were supplied by Merck (Bogotá, Colombia) and they were used as received. Deionized water was used as dispersing phase.

\subsection{Preparation of the waterborne polyurethane/acrylate dispersions}

PTMO, DMPA, NMP (weight ratio 4:1, NMP:DMPA) and DBTDL were placed in $100 \mathrm{~mL}$ four-neck reactor, heated up to $90^{\circ} \mathrm{C}$ and mechanically stirred at $500 \mathrm{rpm}$ under nitrogen atmosphere. After homogenizing the mixture at $90^{\circ} \mathrm{C}$, IPDI was slowly fed into the reactor allowing react for two hours and the $\mathrm{NCO} / \mathrm{OH}$ mole ratio in the prepolymer was maintained at 1.30. Separately, for chain extended dispersions, Bis-GMA and/or BD were diluted in 1/4 of the total amount of ST/ BA used mixture for hybridization (1:1 wt.\% ST/BA). In the case of the end-capped dispersion, all the Bis-GMA and the BD were replaced by the HEMA, following the same procedure. The reactor was cooled down to $60^{\circ} \mathrm{C}$ and that mixture was added, allowing react for two additional hours. Then, the acid groups were neutralized with TEA during $30 \mathrm{~min}$ and the remaining ST/BA mixture (3/4 of the total amount) was fed into the reactor. The temperature was diminished to $30^{\circ} \mathrm{C}$, the stirring was increased up to $2200 \mathrm{rpm}$ and a solution of EDA in distillated water was added to react with the remaining $50 \%$ of NCO groups and the stirring was maintained for one hour. After cooling down to room temperature, an aqueous solution of AA and $\mathrm{H}_{2} \mathrm{O}_{2}$ was added drop by drop under stirring at $250 \mathrm{rpm}$, and let react at $30^{\circ} \mathrm{C}$ during two hours. The concentrations of hydrogen peroxide and ascorbic acid were fixed at 0.1 and $0.002 \mathrm{M}$, respectively. Then, the hybrid dispersion was obtained. The nominal solids content for each dispersion was $30 \mathrm{wt} \%$ based on the polymer weight fraction. Fig. 1 shows the scheme of the synthesis of the hybrid dispersions, and Table 1 shows the composition of waterborne polyurethane/acrylate (WPUA) dispersions.

\subsection{Characterization of the polyurethane/acrylate dispersions}

Mean particle size and particle size distribution of the polyurethane/ acrylate dispersions were obtained in Nanoplus HD (Particulate systems, Micromeritics Instruments, Norcross, GA, USA). To perform the measurement, a drop of the dispersion was added to deionized water container, 30 scans were carried out, and three replicates were measured and averaged.

The $\zeta$ potential measurements of the polyurethane/acrylate dispersions were performed in Zsizer Nano ZS (Malvern Instruments, Worcestershire, United Kingdom). For measurement, $10 \mu \mathrm{L}$ of dispersion were diluted to $1.0 \mathrm{~mL}$ with deionized water. Three replicates were measured and averaged.

$\mathrm{pH}$ of the polyurethane/acrylate dispersions were measured at $24^{\circ} \mathrm{C}$ in Thermo Scientific Orion 3-Star Benchtop pH Meter (Thermo Scientific, Panda garden, Singapore). Three replicates were measured and averaged.

Brookfield viscosity at $25^{\circ} \mathrm{C}$ of the polyurethane/acrylate dispersions was measured in Brookfield LDVE115 viscometer (Brookfield Engineering Laboratories, Middleborough, MA, USA). The measurements were carried out at $100 \mathrm{rpm}$ by using the spindle no. 2 .

Surface tension of the polyurethane/acrylate dispersions was performed by using the Du Nouy's ring method in Phywe dynamometer (Phywe System Gmbh, Gottingen, Germany), equipped with a metal ring of $19.5 \mathrm{~mm}$ diameter. The dispersion was poured into beaker of $11.0 \mathrm{~mL}$ and the ring was placed on the dispersion surface, determining the force $(F)$ necessary to remove the ring. The surface tension $(\gamma)$ was calculated by using Eq. (1) 


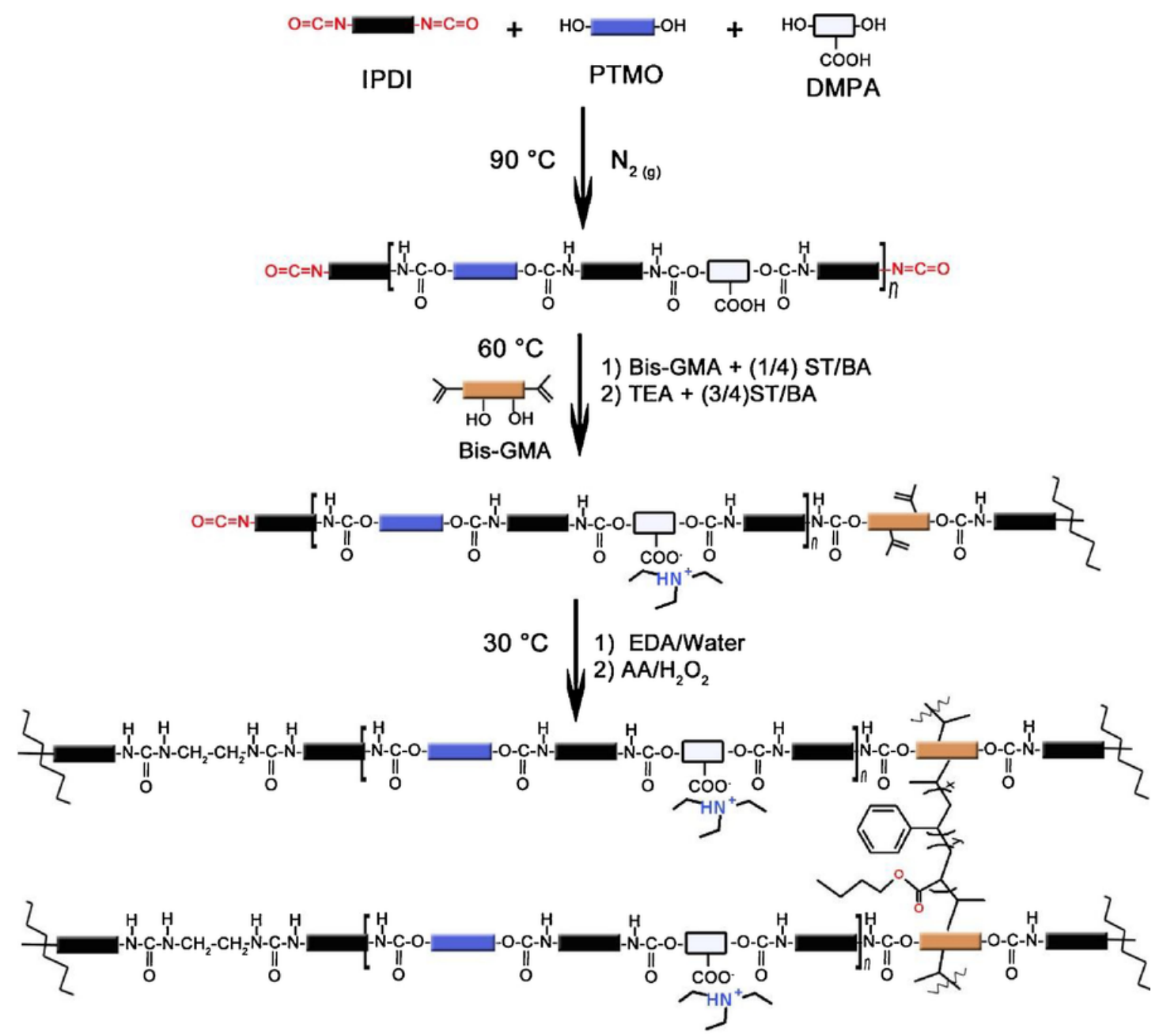

Hybrid WPUD

Fig. 1. Scheme of the synthesis of WPUA dispersion chain extended without BD, with 50\% of Bis-GMA and $50 \%$ EDA (B50 in Table 1).

Table 1

Nomenclature and composition of the hybrid polyurethane/acrylate (WPUA) dispersions.

\begin{tabular}{|c|c|c|c|c|c|}
\hline WPUA & Polyurethane composition ${ }^{\mathrm{a}}$ (molar ratio) & & & $\mathrm{PU}^{\mathrm{b}}(\mathrm{wt} \%)$ & $\mathrm{PA}^{\mathrm{c}}(\mathrm{wt} \%)$ \\
\hline & IPDI/PTMO/DMPA/TEA & HEMA & Bis-GMA/BD/EDA & & $\mathrm{ST} / \mathrm{BA}$ \\
\hline B0 & $2.000 / 0.544 / 0.994 / 0.994$ & 0.000 & $0.000 / 0.231 / 0.231$ & 60 & $20 / 20$ \\
\hline B15 & $2.000 / 0.544 / 0.994 / 0.994$ & 0.000 & $0.069 / 0.162 / 0.231$ & 60 & $20 / 20$ \\
\hline B25 & $2.000 / 0.544 / 0.994 / 0.994$ & 0.000 & $0.115 / 0.115 / 0.231$ & 60 & $20 / 20$ \\
\hline B35 & $2.000 / 0.544 / 0.994 / 0.994$ & 0.000 & $0.162 / 0.069 / 0.231$ & 60 & $20 / 20$ \\
\hline B50 & $2.000 / 0.544 / 0.994 / 0.994$ & 0.000 & $0.231 / 0.000 / 0.231$ & 60 & $20 / 20$ \\
\hline H50 & $2.000 / 0.544 / 0.994 / 0.994$ & 0.462 & $0.000 / 0.000 / 0.231$ & 60 & $20 / 20$ \\
\hline
\end{tabular}

a Based on polyurethane part.

b Polyurethane part, based on dry polymer.

c Butyl acrylate-styrene copolymer part, based on dry polymer.

$\gamma=\frac{F}{4 \pi r}$

where $r$ is the radius of the ring. Four replicates were measured and averaged.

The solids content of the polyurethane/acrylate dispersions were obtained by weight difference before and after water removal. About $0.5 \mathrm{~g}$ of dispersion was poured on Teflon ${ }^{\circledR}$ plate and heated at $40^{\circ} \mathrm{C}$ during $72 \mathrm{~h}$; then, the temperature was increased up to $75^{\circ} \mathrm{C}$ and maintained during $72 \mathrm{~h}$ in order to allow complete evaporation of the sol- vent. The solids content were also corroborated by using a thermobalance.

\subsection{Characterization of the polyurethane/acrylate polymers}

In order to obtain solid hybrid WPUA films, about $1 \mathrm{~mL}$ of WPUA dispersions were placed in Teflon ${ }^{\circledR}$ mold of dimensions $11 \times 2.5 \times 0.05 \mathrm{~cm}$ at $40^{\circ} \mathrm{C}$ during 3 days, and then the temperature was increased up to $75^{\circ} \mathrm{C}$ during 3 additional days. 
The chemical composition of the hybrid WPUA films was determined by infrared spectroscopy in Bruker Tensor 27 spectrometer (Bruker Optik GMbH, Ettlingen, Germany), provided with Fourier transform analysis (FTIR). Measurements were carried out in the attenuated total reflectance mode by using ZnSe prism. An incidence angle of the IR radiation of $45^{\circ}$ was used, and 60 scans were averaged with a resolution of $4 \mathrm{~cm}^{-1}$.

Contact angle measurements at $24^{\circ} \mathrm{C}$ on the hybrid WPUA films were carried out in ILMS 377 goniometer (GBX Instruments, Bourg de Pèage, France). Bi-distilled and deionized water, and diiodomethane (supplied by VWR Chemicals, Fontenay-sous-Bois, France) were used as test liquids. For measurement, the extremes of the films were fixed in tension clamp for assuring that the surface was maintained flat during the measurements. A drop of $3 \mu \mathrm{L}$ of each test liquid was placed on the hybrid WPUA film surface, and the contact angle value was determined $30 \mathrm{~s}$ after drop deposition. For each test liquid, five replicates were measured and averaged.

The surface energy $\left(\gamma_{s}\right)$ of the hybrid WPUA films was determined from water and diiodomethane contact angles by using Owens-Wendt approach - Eq. (2):

$$
\frac{\left(1+\cos \theta_{i}\right) \gamma_{l i}}{\sqrt{\gamma_{l i}^{d}}}=\sqrt{\gamma_{s}^{p}}+\sqrt{\frac{\gamma_{l i}^{p}}{\gamma_{l i}^{d}}} \sqrt{\gamma_{s}^{d}}
$$

where $\gamma_{s}^{p}$ and $\gamma_{s}^{d}$ are the polar and dispersive components of the surface energy respectively, $\theta_{i}$ is the contact angle measured with each test liquid, and

$\gamma_{l i}^{p}$ and $\gamma_{l i}^{d}$ are the polar and dispersive components of the surface tension of the test liquids - water $\left(\gamma_{w}=72, \gamma_{w}^{p}=50.4\right.$ and $\gamma_{w}^{d}=21.6 \mathrm{mN} /$ $\mathrm{m})$ and diiodomethane $\left(\gamma_{D}=50, \gamma_{D}^{p}=2.3\right.$ and $\left.\gamma_{D}^{d}=47.2 \mathrm{mN} / \mathrm{m}\right)$.

The thermal stability of the hybrid WPUA films was determined in TGSD TA thermal balance, model 851e/1600/LF (TA Instruments, New Castle, DE, USA). $10-15 \mathrm{mg}$ of sample was heated under nitrogen atmosphere (flow rate: $100 \mathrm{~mL} / \mathrm{min}$ ). For removing potential water traces in WPUA films, the samples were heated from room temperature to $70^{\circ} \mathrm{C}$ by using a heating rate of $10^{\circ} \mathrm{C} / \mathrm{min}$ and maintained at $70^{\circ} \mathrm{C}$ during $30 \mathrm{~min}$; then, the temperature was increased from 70 up to $800^{\circ} \mathrm{C}$ by using a heating rate of $10^{\circ} \mathrm{C} / \mathrm{min}$.

The viscoelastic properties of the hybrid WPUA films were measured in DMA Q800 instrument (TA Instruments, New Castle, DE, USA) by using tension film geometry. Rectangular test samples of dimensions $10 \times 6 \times 0.3 \mathrm{~mm}$ were used. The experiments were carried out by heating the sample from $-100^{\circ} \mathrm{C}$ up to $95^{\circ} \mathrm{C}$ by using a heating rate of $3{ }^{\circ} \mathrm{C} / \mathrm{min}$, a frequency of $1 \mathrm{~Hz}$, an amplitude of $30 \mu \mathrm{m}$, and a strain of $0.5 \%$. All experiments were carried under nitrogen atmosphere (flow rate: $100 \mathrm{~mL} / \mathrm{min})$.

\subsection{Adhesion measurement of WPUA coatings on stainless steel plate}

The adhesion of the coatings made by applying the hybrid WPUA dispersions on stainless steel 304 was determined by using the cross-cut or cros-hatch test according to ASTM D3359 standard. Cross-cut test determines the percentage of area of a polymeric coating on a substrate removed after making several cuts for making rectangular squares which are removed by using standard adhesive tape. The hybrid WPUA coatings were prepared by pouring the dispersions over stainless steel 304 plate, the thickness was adjusted to $8 \mu \mathrm{m}$ by means of Meyer rod, and then the water was removed in oven at $40{ }^{\circ} \mathrm{C}$ overnight. A multi-blade cutting device 0302001 (Neurtek Instruments S.A., Eibar, Spain) was used for making 6 parallel cuts on the coating surface in perpendicular direction; afterwards, Tesa ${ }^{\circledR}$ adhesive tape was applied on the coating squares made by the cutting device, and the tape was pulled out accounting for the number of removed coating squares. Three replicates were tested and averaged for obtaining the cross-cut adhesion value. The adhesion values were ranked according to the scale given in ASTM D3359 standard that it is summarized in Fig. 2. A cross-cut adhesion value of $5 \mathrm{~B}$ means excellent adhesion, i.e. all coating squares remain on the coated stainless steel plate -, and a cross-cut value of $0 \mathrm{~B}$ means poor adhesion, i.e. the most coating squares are detached from the stainless steel plate.

\section{Results and discussion}

\subsection{Properties of the hybrid polyurethane/acrylate dispersions}

Fig. 3 displays the scheme of the formation of the particles in hybrid WPUA dispersion. The addition of the hydrogen peroxide/ascorbic acid redox pair as initiator of the polymerization produces stable dispersions. The initiation step is promoted by the hydroxyl radicals from the reaction between hydrogen peroxide and ascorbic acid [25-28]. After polyurethane formation and its aqueous dispersion, the polyurethane ionomer helps to stabilize the polymer particles, and the vinyl monomers are absorbed preferably in the polyurethane micelles [29]. The addition of the initiator triggers the radical polymerization of n-butyl acrylate and/or styrene with the grafted Bis-GMA, leaving a hybrid polymer with multiple types of bonding between the polyurethane and the $n$-butyl acrylate-styrene copolymer. The content of Bis-GMA can affect the crosslinking degree inside the particles, the molecular weight of the polymer and the number of ionic groups on the surface. Thus, a higher crosslinking degree can leave trapped ionic groups and inaccessible double $\mathrm{C}=\mathrm{C}$ bonds (Fig. 3 ).

The particle size distribution of the dispersions shows monomodal distributions (Fig. 4). When the chain extension is carried out by using $15 \mathrm{wt} \%$ Bis-GMA, the mean particle size of the hybrid dispersion increases in comparison with the dispersion made without Bis-GMA (B0) (Table 2). The mean particle size of the hybrid dispersions made with $15-35 \mathrm{wt} \%$ Bis-GMA is very similar $(53-55 \mathrm{~nm})$, whereas an increase is produced in the dispersion made with $50 \mathrm{wt} \%$ of Bis-GMA $(60 \mathrm{~nm})$. Un-

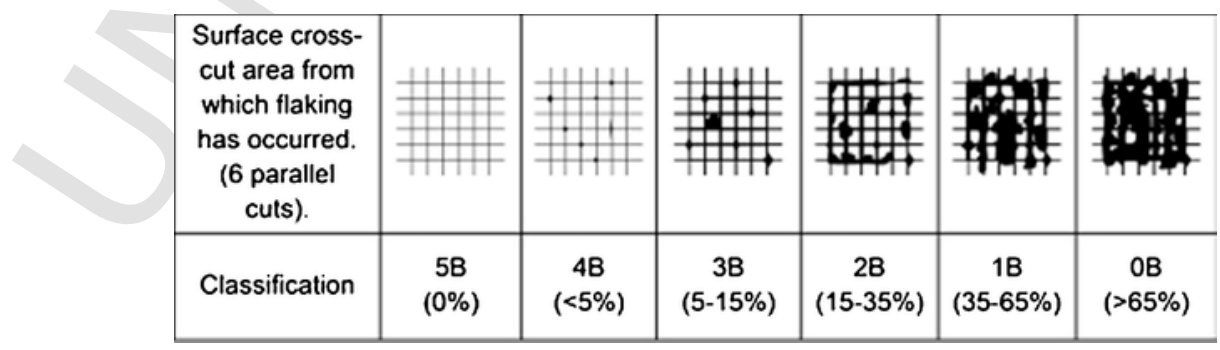

Fig. 2. Cross-cut adhesion scale for coatings according to ASTM D3359 standard. 


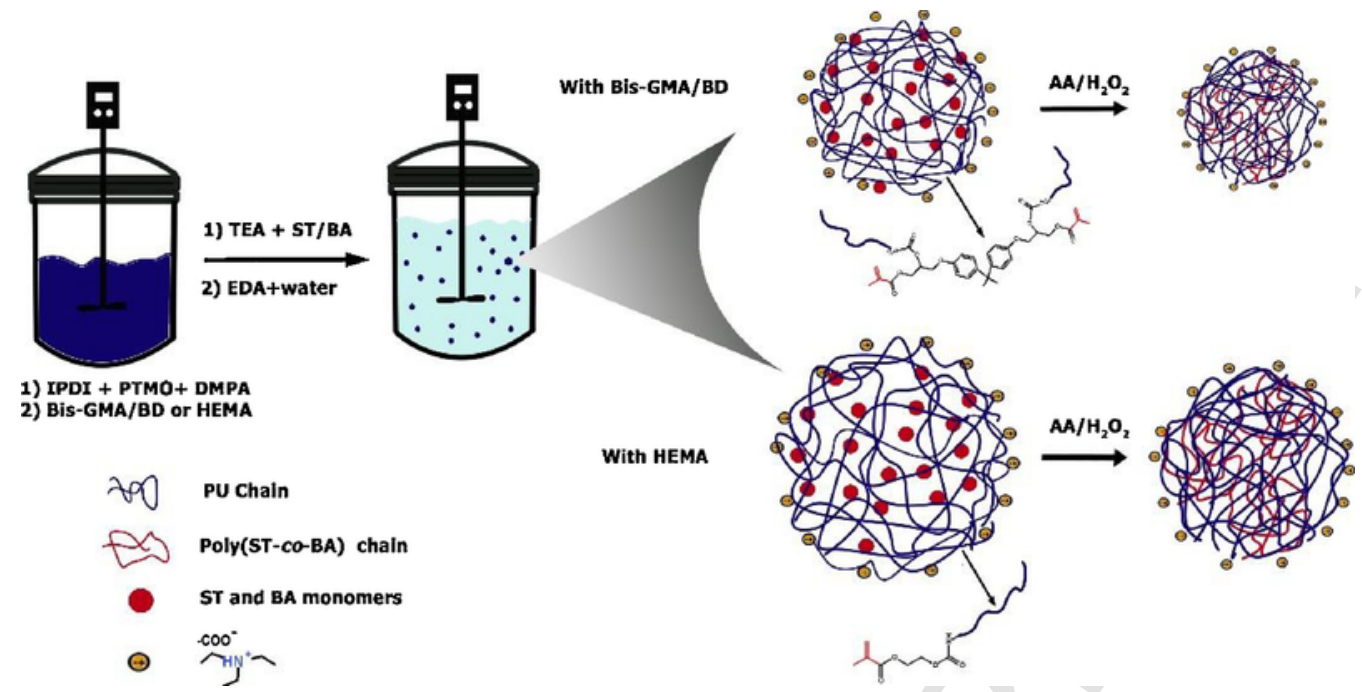

Fig. 3. Scheme of hybrid polyurethane/acrylic particles formation by using Bis-GMA/BD and HEMA as chain extender.

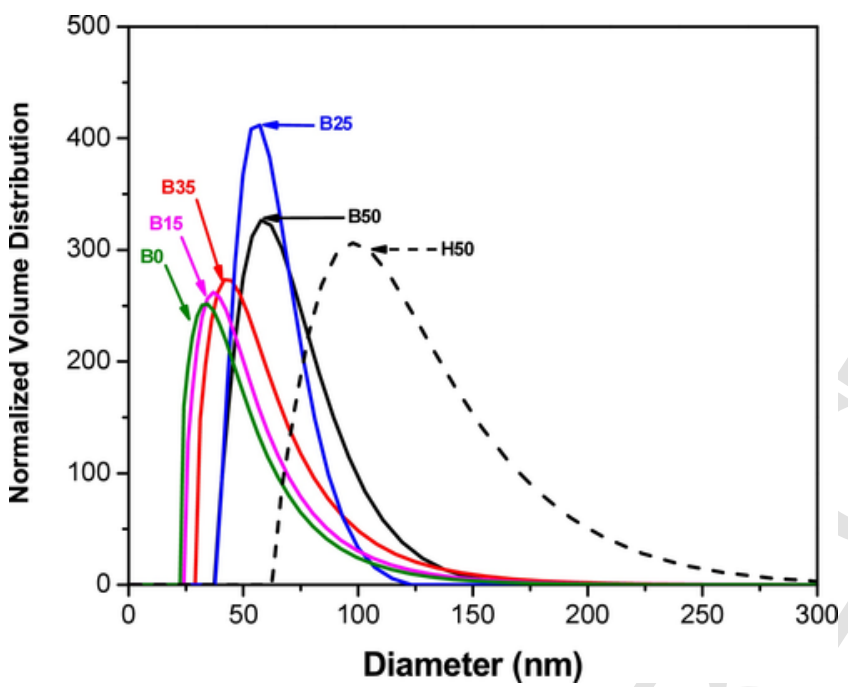

Fig. 4. Particle size distributions of WPUA dispersions.

like to BD chain extender, in the chain extension step with Bis-GMA, the molecular weight of the polymer increases, acting as crosslinking agent between the polyurethane and the $n$-butyl acrylate-styrene copolymer. Therefore, an increase in the mean particle size of the dispersion can be expected, and the variations in the mean particle size of the hybrid WPUA dispersions can be due to the length of the acrylic/styrenic polymer chains and the degree of entanglement among the polymer chains inside the particles. If the amount of Bis-GMA is higher than $35 \mathrm{wt} \%$, the growth of the acrylic/styrenic chains is facilitated, leading to an increment in the mean particle size.

On the other hand, according to Table 2, when Bis-GMA content increases with respect to the one of $\mathrm{BD}$, the mean particle size tends to increase and when the Bis-GMA is replaced by HEMA in the chain extension step (H50 dispersion), the mean particle size increases almost twice as compared to the dispersion without Bis-GMA (B50 dispersion). This increasing of the particle size depends of the way by which HEMA reacts as compared to Bis-GMA does. Bis-GMA/BD reacts with two end NCO groups in the same particle, increasing the length of the polyurethane chain and leaving two double $\mathrm{C}=\mathrm{C}$ bonds per molecule, which will react subsequently with $n$-butyl acrylate and/or styrene (Fig. 3). On the other hand, a molecule of HEMA reacts with only one NCO end group of the polyurethane chain and it quenches the chain growth of the polyurethane chain. Furthermore, after water dispersion and chain extension with EDA, both kinds of polyurethane chains can increase their length, however, Bis-GMA/BD extended polymers must be larger than HEMA ones.

Prior to radical polymerization, the larger is the chain length of the polyurethane, the larger is the entanglement among the chains inside the individual particles and the shorter is the particle size. After radical polymerization, promoted by the redox pair, the mean particle size should decrease due to volumetric contraction promoted by crosslinking copolymerization reactions. The lower mean particle size of B0 dispersion could be related to the more efficient chain extension with BD than with Bis-GMA, because of the primary $-\mathrm{OH}$ groups of $\mathrm{BD}$ are much more reactive than the secondary - $\mathrm{OH}$ groups of Bis-GMA towards isocyanate groups. However, the $\mathrm{B} 0$ does not contain polymerizable double $\mathrm{C}=\mathrm{C}$ bonds groups. The hybrid WPUA polymer made with Bis-GMA would lead to shorter vinyl chains due to the two double $\mathrm{C}=\mathrm{C}$ bonds in Bis-GMA per molecule that will create higher density of acrylic/vinyl chains per surface unit, and consequently a decrease of the mean particle size can be expected (Fig. 3).

The $\zeta$ potential of the polyurethane/acrylate dispersions is related to their colloidal stability. According to Table 2, all dispersions have negative values, due to the acid groups of DMPA neutralized with TEA, ranging from -57 to $-42 \mathrm{mV}$, which suggests good electrostatic stabi-

Table 2

Some properties of WPUA dispersions.

\begin{tabular}{|c|c|c|c|c|c|c|}
\hline WPUA & Mean particle size (nm) & $\zeta$ potential $(\mathrm{mV})$ & Viscosity (mPa.s) & $\mathrm{pH}$ & Surface tension $(\mathrm{mN} / \mathrm{m})$ & Solids content (wt $\%$ ) \\
\hline B0 & 45 & -51 & 1.7 & 7.3 & 19.9 & 27.3 \\
\hline B15 & 55 & -51 & 1.4 & 7.4 & 20.7 & 26.5 \\
\hline B25 & 55 & -49 & 1.4 & 7.4 & 20.3 & 25.3 \\
\hline B35 & 53 & -57 & 1.2 & 7.4 & 20.3 & 26.8 \\
\hline B50 & 60 & -42 & 1.5 & 7.1 & 19.9 & 26.8 \\
\hline H50 & 109 & -52 & 1.2 & 6.7 & 19.6 & 26.6 \\
\hline
\end{tabular}


lization of the particles. The highest value of $\zeta$ potential (i.e., less negative) corresponds to the dispersion made with $50 \mathrm{wt} \%$ Bis-GMA due to an increase in the crosslinking degree between the polyurethane and the $n$-butyl acrylate-styrene copolymer, which generates lower mobility of the chains and confines the acidic groups toward the inner part of the particles, decreasing the number of ionic groups at the surface. Because all hybrid WPUA dispersions have the same concentration of internal emulsifier, in general, the value of $\zeta$ does not change abruptly.

On the other hand, the Brookfield viscosities of the hybrid WPUA dispersions are very low (Table 2) and they seem to be related to their mean particle size. Thus, the highest viscosity corresponds to B0 dispersion that also has the smallest particle size; contrarily, the lowest viscosity corresponds to the dispersion with the highest mean particle size (H50 dispersion). However, B35 dispersion does not follow the same trend since it has the smallest mean particle size and the lowest viscosity. Because of this dispersion has the most negative $\zeta$ potential, its surface possesses more charged groups that would favor the water dispersion that will likely produce low viscosity. Furthermore, the solids content of the hybrid WPUA dispersions are somewhat similar and close to $27 \mathrm{wt} \%$, irrespective of the amount of Bis-GMA and the addition of HEMA, since it only depends on the initial mass of the monomers (Table 2 ). On the other hand, the $\mathrm{pH}$ values of the dispersions are 7.3-7.4 except for B50 and $\mathrm{H} 50$ dispersions that show lower pH values, likely due to a different concentration of ionic groups on the surface of the particles caused by differences in morphology. Bis-GMA provides more dense entangled particles as compared to HEMA, allowing easier hydronium exchange.

Additionally, the surface tensions of the hybrid WPUA dispersions are similar, irrespective of their Bis-GMA content or HEMA addition, and they are near $20 \mathrm{mN} / \mathrm{m}$. The surface tension values of the dispersions are lower than other reported in the literature when HEMA is used as crosslinking agent $[6,19,30]$. the surface tension of the polyurethane dispersions are close to $40 \mathrm{mN} / \mathrm{m}$, although the DMPA content used was lower than the one used in this study ( $8 \mathrm{wt} \%$ with respect to the polyurethane part). Furthermore, Kim and Lee[31] reported a decrease of the surface tension until $36 \mathrm{mN} / \mathrm{m}$ when PTMEG is used instead of PEG or PPG. In another study, Wang et al. [32] reported that the surface tension of polyurethane dispersions decreased as the DMPA content increased in the range of 2.37-4.27 wt $\%$ DMPA, and the lowest surface tension value was $40 \mathrm{mN} / \mathrm{m}$. On the other hand, Chen [33] reported that the surface tension of different anionomers of polyurethane made with various counterions, including TEA, decreases until $42 \mathrm{mN} / \mathrm{m}$ when the concentration of salt groups per liter increases, showing that concentration was important. Finally, Chwang et al. [34] attributed the decrease in surface tension of ionomeric polyurethane dispersions made with DMPA to the increase of the hydrophobic groups of ionomer molecules adsorbed at the air-water interface. In our case, the hybrid WPUA dispersions can be considered as polyelectrolytes which are stabilized by the ionic grafted groups to the backbone chain polymer particles [35].

\subsection{Characterization of the solid hybrid polyurethane/acrylate films}

ATR-IR spectra (Fig. 5) of the solid hybrid WPUA films show the characteristic bands of these polymers $[6,19,30]$, and, in general, the ATR-IR spectra of all WPUA films are quite similar. The ATR-IR spectra of the solid WPUA films shows the absence of $-\mathrm{N}=\mathrm{C}=\mathrm{O}$ stretching band at $2270 \mathrm{~cm}^{-1}$, indicating complete reaction of the isocyanate groups. The ATR-IR spectra show the characteristic bands of the polyurethanes [36-38]: $\mathrm{N}-\mathrm{H}$ stretching of urethane at $3324 \mathrm{~cm}^{-1}, \mathrm{C}$ $-\mathrm{H}$ stretching at 2933 and $2854 \mathrm{~cm}^{-1}, \mathrm{C}=\mathrm{O}$ stretching due to urea, urethane and ester groups $\left(1750-1650 \mathrm{~cm}^{-1}\right), \mathrm{C}-\mathrm{N}$ stretching and $\mathrm{N}$ $-\mathrm{H}$ bending of the urea groups at $1537 \mathrm{~cm}^{-1}$, asymmetric and sym-

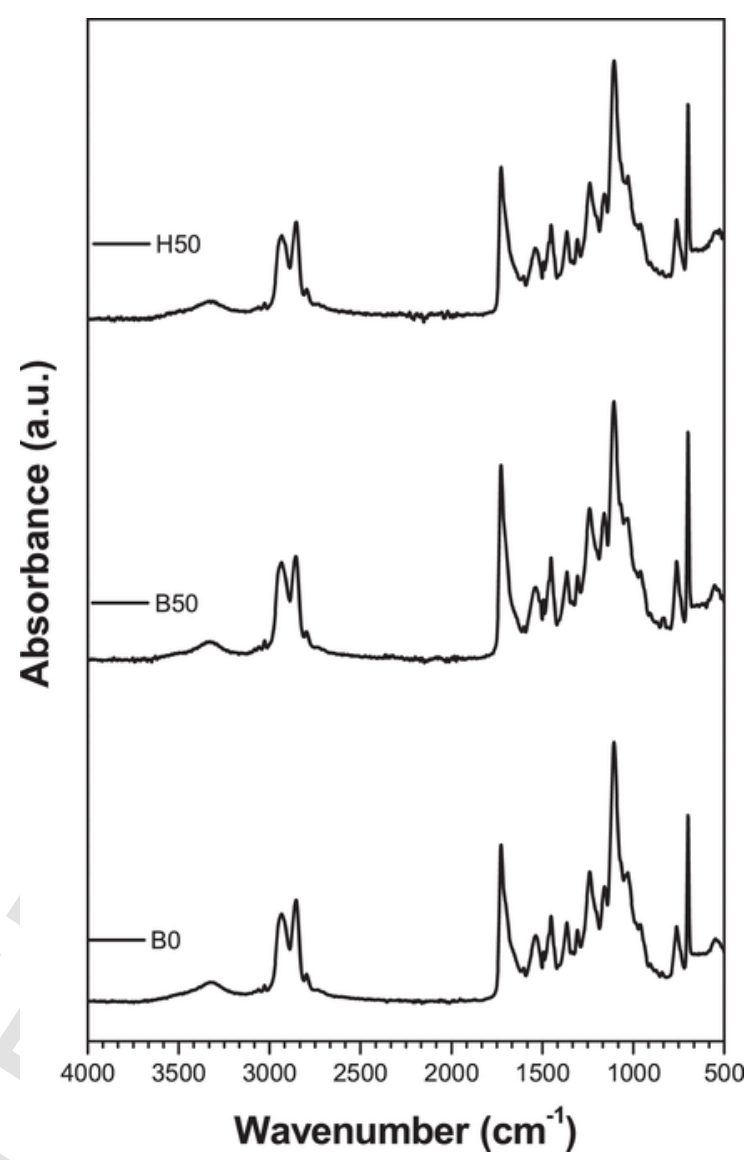

Fig. 5. ATR-IR spectra of some hybrid polyurethane/acrylate films.

metric stretching of $\mathrm{N}-\mathrm{CO}-\mathrm{O}$ group at 1240 and $1032 \mathrm{~cm}^{-1}$ respectively, and $\mathrm{C}-\mathrm{O}-\mathrm{C}$ stretching of urethane at 1157 and $1107 \mathrm{~cm}^{-1}$. On the other hand, the characteristic out-of-plane bending of styrene [22] appears at 760 and $700 \mathrm{~cm}^{-1}$, suggesting that polymerization of styrene, promoted by the redox pair, is produced because of, apart from this monomer, only the Bis-GMA presents aromatic groups in its structure, and this can be related to the height of the band at $700 \mathrm{~cm}^{-1}$. Furthermore, the absence of the band at $1638 \mathrm{~cm}^{-1}$, assigned to the symmetric stretching of the double $\mathrm{C}=\mathrm{C}$ bond, demonstrates the efficacy of the redox system in the radical polymerization.

The water $\left(\theta_{\mathrm{w}}\right)$ and diiodomethane $\left(\theta_{\mathrm{d}}\right)$ contact angles on the solid hybrid WPUA films are given in Fig. 6 . The water contact angle values of the films are high and similar between them, and the lowest corresponds to the one made with $15 \mathrm{wt} \%$ Bis-GMA. The high hydrophilicity of B15 film could be ascribed to more hydrophilic groups of the urethane moieties exposed to the film surface due to a the low Bis-GMA content. However, when the amount of Bis-GMA in the hybrid WPUA films increases, the water contact angles are basically constant due to the higher density of vinyl/acrylic chains surrounding the polyurethane particles which makes them more hydrophobic. On the other hand, the diiodomethane contact angles on the hybrid WPUA films decrease by increasing their Bis-GMA content, and they are lower than for the film made with HEMA. Because of the dioodomethane is non-polar, the decrease in contact angle indicated an increase in hydrophobicity of the films for amounts of Bis-GMA of $35 \mathrm{wt} \%$ or higher. Furthermore, the lower diiodomethane contact angle of the film made with HEMA is an indication of higher hydrophobicity. A possible explanation for this behavior can be the higher occlusion of the carboxylic groups by increasing the crosslinking degree. Besides, once the water stars to evaporate 


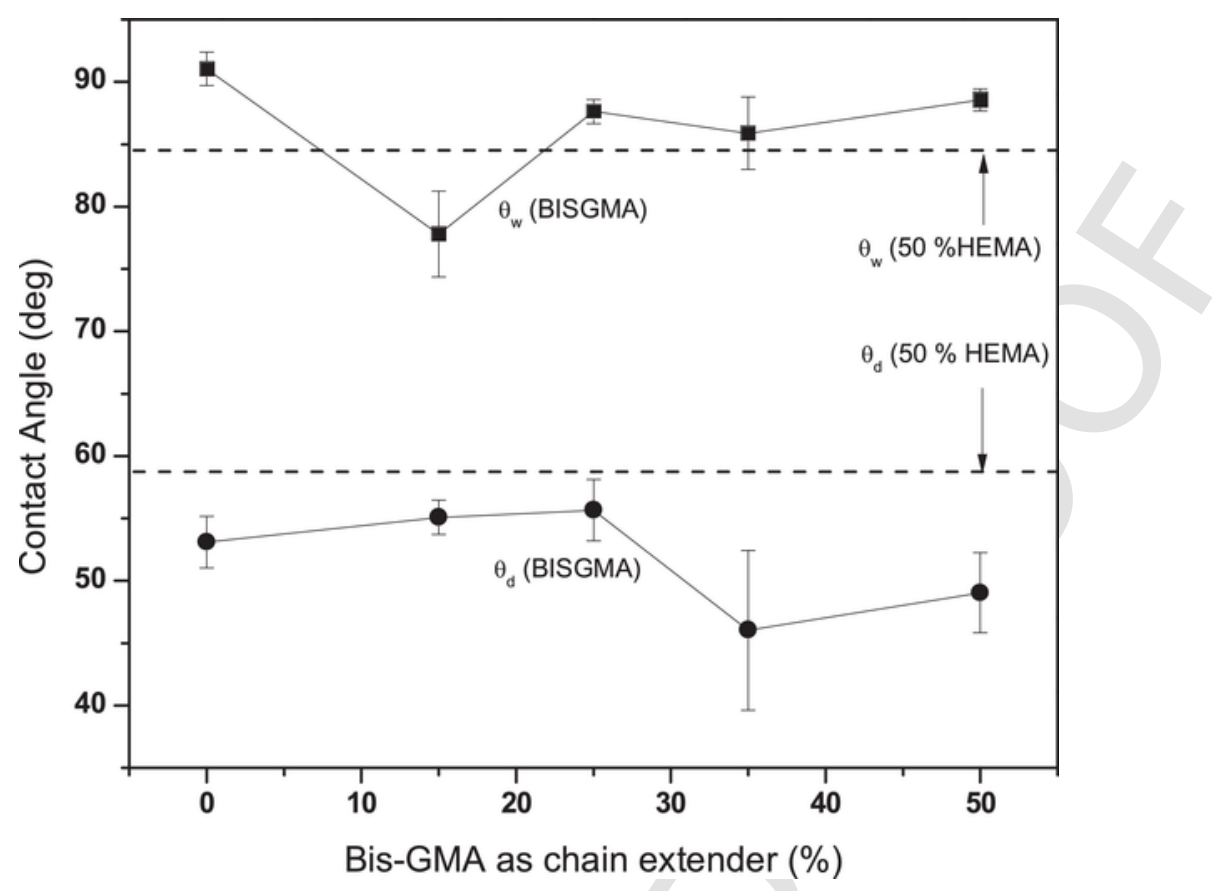

Fig. 6. Water and diiodomethane contact angle values of hybrid polyurethane/acrylate films as a function of their Bis-GMA content.

during the hybrid polymer film formation, the hydrophobic segments of the polymer tend to migrate to the surface to be in contact with the air.

From the contact angle values of the hybrid WPUA films, their surface free energy and their polar and dispersive components can be obtained. According to Table 3, the films have relatively low surface free energies (between 31 and $36 \mathrm{~mJ} / \mathrm{m}^{2}$ ) which are somewhat similar irrespective of the Bis-GMA content or the addition of HEMA. The relatively low surface free energies of the hybrid polyurethane/acrylate films corresponds to relatively low polarity due to the dominant presence of acrylate moieties on the surface. Therefore, the dispersive component is major $\left(25-33 \mathrm{~mJ} / \mathrm{m}^{2}\right)$ in the surface energy of the films and the polar component is low $\left(2-8 \mathrm{~mJ} / \mathrm{m}^{2}\right)$; however, the polar component is more important and the dispersive component is lower in the film made with $15 \mathrm{wt} \%$ Bis-GMA due to the presence of carboxylic groups of the polyurethane part on the surface.

Fig. 7a shows the TGA plots of the hybrid WPUA films. B0 film shows the lowest thermal stability because of it does not contain double $\mathrm{C}=\mathrm{C}$ bonds in the structure. The thermal stability increases as the Bis-GMA content increases, whereas the film prepared with HEMA shows an intermediate thermal stability (Table 4). The variation of the derivative of the mass as a function of the temperature (Fig. 7b) shows three differentiate thermal events during polymer decomposition with maxima at about 260,320 and $400^{\circ} \mathrm{C}$. These decompositions are asso-

Table 3

Surface free energy $\left(\gamma_{s}\right)$ and dispersive $\left(\gamma_{s}^{d}\right)$ and polar $\left(\gamma_{s}^{p}\right)$ components of the polyurethane/ acrylate films containing different amounts of Bis-GMA or HEMA.

\begin{tabular}{|c|c|c|c|}
\hline $\begin{array}{l}\text { WPUAD } \\
\text { film }\end{array}$ & $\gamma_{s}^{p} \quad(\mathrm{~mJ} / \mathrm{m} 2)$ & $\gamma_{s}^{d}(\mathrm{~mJ} / \mathrm{m} 2)$ & $\gamma\left(\mathrm{m} J / \mathrm{m}^{2}\right)$ \\
\hline в0 & 2 & 30 & 32 \\
\hline B15 & 8 & 26 & 34 \\
\hline B25 & 3 & 28 & 31 \\
\hline B35 & 3 & 33 & 36 \\
\hline B50 & 2 & 32 & 34 \\
\hline H50 & 5 & 25 & 30 \\
\hline
\end{tabular}

ciated to the decomposition of urethane hard segment $\left(260^{\circ} \mathrm{C}\right)$, urea hard segment $\left(320^{\circ} \mathrm{C}\right)$ and polyol soft segment $\left(400^{\circ} \mathrm{C}\right)$ [39] overlapped with the $n$-butyl acrylate-styrene copolymer thermal decomposition [40]. The addition of Bis-GMA displaced the decomposition temperature of urethane domains to lower temperature and the one of the urea domains at higher temperature (Table 5), indicating a change in the degree of phase separation in the WPUA films. Furthermore, the temperature of decomposition of the soft segments and styrene/acrylate segments of the films increases by increasing the Bis-GMA content, which suggest higher crosslinking degree between polyurethane and acrylate, resulting in a slight increase in thermal stability. This increase could be attributed only to Bis-GMA, because of the soft segments and the styrene/n-butyl acrylate copolymer show similar decomposition temperatures and all films contain the same amount of copolymer. On the other hand, H50 film has slightly lower thermal stability with respect to that of B50, because of the lower crosslinking degree of H50 film, that would allow better oxygen diffusion through the polymeric matrix and thus an earlier thermal decomposition.

The viscoelastic properties of the hybrid WPUA films were measured by DMA by using tension film geometry. Typical viscoelastic behavior for hybrid polymers is obtained [9,10,41-44]. Thus, the storage moduli decrease as the temperature increases (Fig. 8a), and the glassy region below $-60^{\circ} \mathrm{C}$, the glass transition, the rubbery plateau and the softening region can be distinguished. The addition of Bis-GMA increases the storage modulus in the glassy region and at the rubbery plateau of the films, more markedly for B15. On the other hand, the storage modulus at the rubbery plateau of the film made with HEMA is lower than for the WPUA films made with Bis-GMA. The variation in the viscoelastic properties of the polyurethane/acrylate films can be better distinguished in Fig. 8b. In general, the variation of $\tan \delta$ as a function of the temperature (Fig. 8b, Table 6) shows the existence of two structural relaxations corresponding to the soft and hard segments in the hybrid WPUA films. The polymer without Bis-GMA (B0) shows one additional structural relaxation at $22^{\circ} \mathrm{C}$ that could correspond to vinyl/acrylic chains as this value agrees well with the glass transition temperature predicted for copolymers of styrene and butyl acrylate [45]. The crosslinking produces by adding Bis-GMA or HEMA causes 


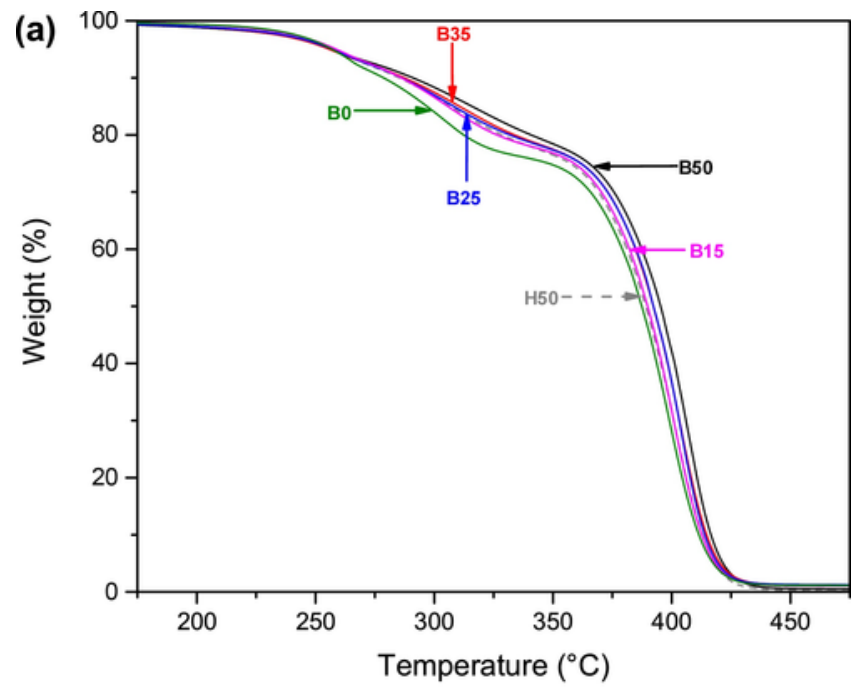

Table 5

Weight lost events in the thermal decomposition of hybrid WPUA films.

\begin{tabular}{llll}
\hline WPUA & Weight loss (wt\%) & Temperature $\left({ }^{\circ} \mathrm{C}\right)$ & Residue $(\%)$ \\
\hline B0 & 9 & 264 & 1 \\
& 15 & 304 & \\
B15 & 75 & 399 & 1 \\
& 7 & 262 & \\
& 15 & 305 & 1 \\
B25 & 76 & 400 & \\
& 8 & 261 & 1 \\
& 15 & 306 & \\
B35 & 76 & 403 & 1 \\
& 7 & 259 & \\
B50 & 14 & 312 & \\
& 77 & 403 & \\
& 7 & 260 & \\
H50 & 14 & 316 & \\
& 78 & 407 & \\
& 15 & 264 & \\
& 77 & 306 & \\
\hline
\end{tabular}
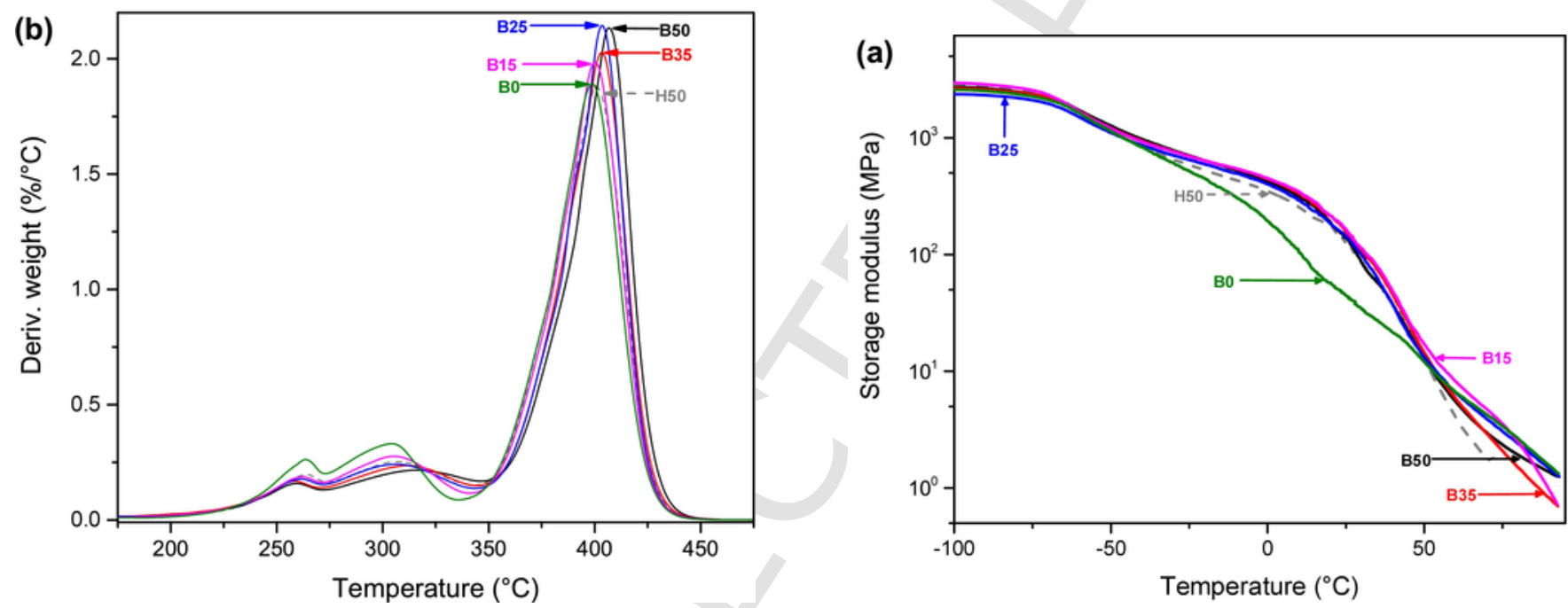

Fig. 7. Variation of the weight (a) and the derivative of the weight (b) as function of the temperature for hybrid polyurethane/acrylate films. TGA experiments.

Table 4

Temperatures at which $5\left(\mathrm{~T}_{5 \%}\right)$ and $50\left(\mathrm{~T}_{50 \%}\right) \mathrm{wt} \%$ are lost, and temperature of maximum decomposition of the hybrid WPUA films. TGA experiments.

\begin{tabular}{llll}
\hline WPUAD film & $\mathrm{T}_{5 \%}\left({ }^{\circ} \mathrm{C}\right)$ & $\mathrm{T}_{50 \%}\left({ }^{\circ} \mathrm{C}\right)$ & $\mathrm{T}_{\max }\left({ }^{\circ} \mathrm{C}\right)$ \\
\hline B0 & 254 & 387 & 399 \\
B15 & 254 & 390 & 400 \\
B25 & 254 & 400 & 403 \\
B35 & 253 & 392 & 403 \\
B50 & 255 & 395 & 407 \\
H50 & 254 & 389 & 401 \\
\hline
\end{tabular}

the disappearance of this structural relaxation [10]. The temperature at which the relaxation of the soft segments appears is not changing noticeably by adding Bis-GMA or HEMA, but the value of tan delta decreases, indicating higher degree of crosslinking; the lowest tan delta value corresponds to B35. On the other hand, the temperature at which the structural relaxation of the hard segments appears is similar in B0 and in the film made with HEMA, but is higher in the WPUA films made with Bis-GMA. More interestingly, the tan delta value of the film in the structural relaxation of the hard segments increases noticeably by increasing the Bis-GMA content, indicating lower interactions between the hard segments because of the change in the degree of phase

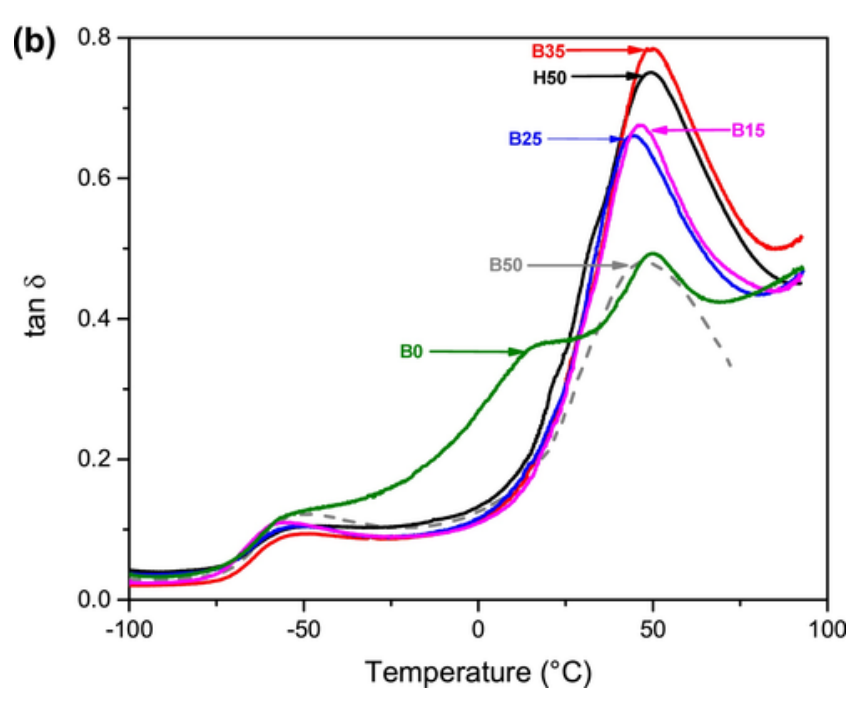

Fig. 8. Variation of the storage modulus (a) and $\tan \delta$ (b) as function of the temperature for polyurethane/acrylate films.

separation induced by the acrylate moiety crosslinked by Bis-GMA. On the other hand, similar viscoelastic behavior can be distinguished in B0 and $\mathrm{H} 50$ (except for the structural relaxation that appears in B0 only). 
Table 6

Temperature and maximum of $\tan \delta$ in the structural relaxations of hybrid WPUA films. DMA experiments.

\begin{tabular}{lllll}
\hline WPUA film & $\mathrm{T}_{1}\left({ }^{\circ} \mathrm{C}\right)$ & $\tan \delta_{1}$ & $\mathrm{~T}_{2}\left({ }^{\circ} \mathrm{C}\right)$ & $\tan \delta_{2}$ \\
\hline B0 $^{\mathrm{a}}$ & -52 & 0.12 & 50 & 0.49 \\
$\mathrm{~B} 15$ & -54 & 0.11 & 46 & 0.67 \\
$\mathrm{~B} 25$ & -50 & 0.10 & 44 & 0.66 \\
B35 & -48 & 0.09 & 50 & 0.78 \\
B50 & -47 & 0.11 & 50 & 0.75 \\
H50 & -53 & 0.17 & 50 & 0.48 \\
\hline
\end{tabular}

a Shows a maximum at $22^{\circ} \mathrm{C}$ and $\tan (\delta)=0.37$.

The hybrid polyurethane/acrylate dispersions were applied on stainless steel 304 plates for obtaining coatings which adhesion was tested by the cross-cut test. The adhesion of the hybrid polyurethane/acrylate coatings improves by adding Bis-GMA, even in small amounts. In the coating made without Bis-GMA, low adhesion is obtained and an important amount of coating is removed (Fig. 9). The addition of $15-35 \mathrm{~mol} \%$ Bis-GMA improves the adhesion and reduces the amount of removed coating, the higher is the Bis-GMA content, the higher is the cross-cut adhesion. This trend could be explained due to the increase of the surface free energy of the hybrid WPUA films produced by increasing their Bis-GMA content, in addition to their higher degree of cross-linking. In fact, optimal adhesion (5B) is obtained in the coating made with 35 mol\% Bis-GMA (Fig. 9), and this WPUA film shows the highest surface free energy. However, the addition of $50 \mathrm{~mol} \%$ Bis-GMA decreases the adhesion due to high crosslink density in the hybrid polymer, which increases the cohesive forces and lessens the adhesion forces to the steel.

\section{Conclusions}

Stable hybrid waterborne polyurethane/acrylate dispersions with particle size in the nanometric scale were successfully prepared by auto-emulsification process using ascorbic acid/hydrogen peroxide radical initiator. In this study, Bis-GMA was first time reported as both chain extender and grafting agent. By using Bis-GMA, it was possible to obtain hybrid dispersion with half particle size of those obtained when the conventional HEMA grafting agent was used, besides of getting higher $\zeta$ potential. The polyurethane ionomers acted as good emulsifying agent helping to stabilize the mixture of $n$-butyl acrylate and styrene monomers. Even more, the surface tension of the

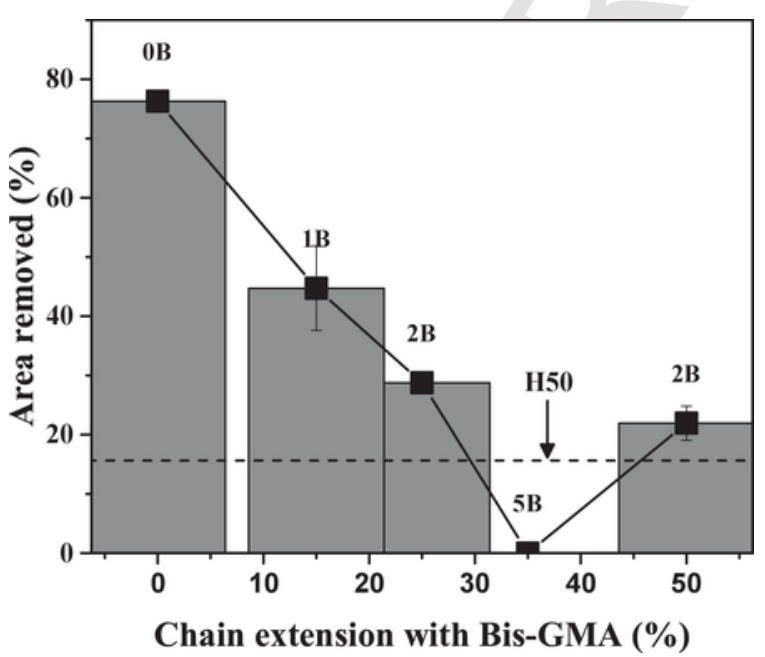

Fig. 9. Percentage of hybrid polyurethane/acrylate coating removed during cross-cut test as a function of their Bis-GMA content. The percentage of area removed during cross-cut test for $\mathrm{H} 50$ coating is given as reference. polyurethane/acrylate dispersions was very low (about $20 \mathrm{~mJ} / \mathrm{m}^{2}$ ), and the viscosity too even they contain $27 \mathrm{wt} \%$ solids content. The incorporation of grafting agents increased the thermal stability of the hybrid WPUA films, the higher was the Bis-GMA content, the higher was the thermal stability. Bis-GMA incorporation into the polyurethane structure caused hybridization and this was evidenced by the overlapping of the $\mathrm{T}_{\mathrm{g}}$ associated to polyurethane hard segments with the $\mathrm{T}_{\mathrm{g}}$ of $n$-butyl acrylate-styrene copolymer. On the other hand, the hybrid WPUAs prepared with Bis-GMA showed higher $\mathrm{T}_{g}$ and storage modulus than the ones in physical blends of polyurethane and acrylate. Finally, the adhesion of hybrid polyurethane/acrylate coatings on stainless steel increased by adding Bis-GMA content, the best adhesion was obtained for the WPUA made with $35 \mathrm{wt} \%$ Bis-GMA. This is a consequence of the high surface free energy and the adequate crosslinking degree between the polyurethane and acrylate chains.

\section{Acknowlegment}

The authors thank to the University of Antioquia for the "Estudiante Instructor" Grant.

\section{References}

[1] B.K. Kim, Aqueous polyurethane dispersions, Colloid Polym. Sci. 274 (1996) 599-611, https://doi.org/10.1007/BF00653056.

[2] X. Zhou, Y. Li, C. Fang, S. Li, Y. Cheng, W. Lei, X. Meng, Recent advances in synthesis of waterborne polyurethane and their application in water-based ink: a review, J. Mater. Sci. Technol. 31 (2015) 708-722, https://doi.org/10.1016/j.jmst. 2015.03.002

[3] S.A. Madbouly, J.U. Otaigbe, Recent advances in synthesis, characterization and rheological properties of polyurethanes and POSS/polyurethane nanocomposites dispersions and films, Prog. Polym. Sci. 34 (2009) 1283-1332, https://doi.org/10. 1016/j.progpolymsci.2009.08.002.

[4] D. Kukanja, J. Golob, A. Zupančič-Valant, M. Krajnc, The structure and properties of acrylic-polyurethane hybrid emulsions and comparison with physical blends, $\mathrm{J}$. Appl. Polym. Sci. 78 (2000) 67-80, https://doi.org/10.1002/ 1097-4628(20001003)78:1 <67::AID-APP100 > 3.0.CO;2-4

[5] C. Wang, F. Chu, C. Graillat, A. Guyot, C. Gauthier, J.P. Chapel, Hybrid polymer latexes: acrylics-polyurethane from miniemulsion polymerization: properties of hybrid latexes versus blends, Polymer (Guildf). 46 (2005) 1113-1124, https://doi. org/10.1016/j.polymer.2004.11.051

[6] H. Xu, D. Yang, Q. Guo, Y. Wang, W. Wu, F. Qiu, Waterborne polyurethane-acrylate containing different polyether polyols: preparation and properties, Polym. Plast. Technol. Eng. 51 (2011) 50-57, https://doi.org/10.1080/03602559.2011. 617403.

[7] V.D. Athawale, M.A. Kulkarni, Preparation and properties of urethane/acrylate composite by emulsion polymerization technique, Prog. Org. Coatings 65 (2009) 392-400, https://doi.org/10.1016/j.porgcoat.2009.03.004.

[8] X. Zhu, X. Jiang, Z. Zhang, X.Z. Kong, Influence of ingredients in water-based polyurethane-acrylic hybrid latexes on latex properties, Prog. Org. Coatings 62 (2008) 251-257, https://doi.org/10.1016/j.porgcoat.2007.12.006.

[9] M. Li, Z. Zheng, S. Liu, W. Wei, X. Wang, Effect of prepolyurethane on the performances of poly(acrylates-co-urethane) copolymer, J. Appl. Polym. Sci. 118 (2010) 3203-3210, https://doi.org/10.1002/app.32761.

[10] C. Tian, Q. Zhou, L. Cao, Z. Su, X. Chen, Effect of polyurethane molecular weight on the properties of polyurethane-poly(butyl methacrylate) hybrid latex prepared by miniemulsion polymerization, J. Appl. Polym. Sci. 124 (2012) 5229-5235, https://doi.org/10.1002/app.34149.

[11] O.R. Pardini, J.I. Amalvy, FTIR, 1H-NMR spectra, and thermal characterization of water-based polyurethane/acrylic hybrids, J. Appl. Polym. Sci. 107 (2008) 1207-1214, https://doi.org/10.1002/app.27188.

[12] E. Degrandi-Contraires, R. Udagama, E. Bourgeat-Lami, T. McKenna, K. Ouzineb, C. Creton, Mechanical properties of adhesive films obtained from PU-acrylic hybrid particles, Macromolecules 44 (2011) 2643-2652, https://doi.org/10.1021/ ma2000702.

[13] Y. Reyes, A. Lopez, J.M. Asua, Modeling the microstructure of acrylic-polyurethane hybrid polymers synthesized by miniemulsion polymerization, Macromol. React. Eng. 5 (2011) 352-360, https://doi.org/10.1002/mren.201100010.

[14] H. Pan, D. Chen, A strategy for preparation of anionic Polyurethane/Acrylate emulsions, Polym. Plast. Technol. Eng. 47 (2008) 595-599, https://doi.org/10 1080/03602550802059345

[15] C. Wang, F. Chu, A. Guyot, C. Gauthier, F. Boisson, Hybrid acrylic-polyurethane latexes: emulsion versus miniemulsion polymerization, J. Appl. Polym. Sci. 101 (2006) 3927-3941, https://doi.org/10.1002/app.22889.

[16] P.J. Peruzzo, P.S. Anbinder, O.R. Pardini, J.R. Vega, J.I. Amalvy, Influence of diisocyanate structure on the morphology and properties of waterborne polyurethane-acrylates, Polym. J. 44 (2012) 232-239, https://doi.org/10.1038/pj. 2011.111.

[17] M. Li, E.S. Daniels, V. Dimonie, E.D. Sudol, M.S. El-Aasser, Preparation of Polyurethane/Acrylic hybrid nanoparticles via a miniemulsion polymerization process, Macromolecules 38 (2005) 4183-4192, https://doi.org/10.1021/ma048141z. 
[18] A. Lopez, E. Degrandi-Contraires, E. Canetta, C. Creton, J.L. Keddie, J.M. Asua, Waterborne polyurethane-acrylic hybrid nanoparticles by miniemulsion polymerization: applications in pressure-Sensitive adhesives, Langmuir 27 (2011) 3878-3888, https://doi.org/10.1021/la104830u.

[19] M.Q. He, J.C. Xu, F.X. Qiu, X.N. Chen, Preparation, characterization, and property analysis of environmentally friendly waterborne polyurethane-acrylate, Int. J. Polym. Anal. Charact. 18 (2013) 211-223, https://doi.org/10.1080/1023666x. 2013.755657.

[20] D. Yang, F. Ye, X. Rong, Waterborne polyurethane-acrylic hybrid polymer based on PTMEG: physical and mechanical properties, J. Mater. Sci. Eng. Adv. Technol. 6 (2012) 19-28.

[21] H. Xin, Y.-D. Shen, X.-R. Li, Synthesis and properties of cationic polyurethane-fluorinated acrylic hybrid latexes by emulsifier-free emulsion polymerization and the solvent-free method, Polym. Bull. 67 (2011) 1849-1863, https://doi.org/10.1007/ s00289-011-0523-y.

[22] Y.-Z. Jin, Y.B. Hahn, K.S. Nahm, Y.-S. Lee, Preparation of stable polyurethane-polystyrene copolymer emulsions via $\{$ RAFT $\}$ polymerization process, Polymer (Guildf) 46 (2005) 11294-11300, https://doi.org/10.1016/j. polymer.2005.10.049.

[23] Z. Pan, H. Hao, Y. Zhao, J. Li, H. Tan, Q. Fu, Preparation of hydrocarbon/fluorocarbon double-chain phospholipid polymer brusheson polyurethane films by \{ATRP\}, Colloids Surf. B Biointerfaces 128 (2015) 36-43, https://doi.org/10. 1016/j.colsurfb.2015.02.012.

[24] R. Udagama, E. Degrandi-contraires, C. Creton, C. Graillat, T.F.L. Mckenna, E. Bourgeat-lami, Synthesis of acrylic À polyurethane hybrid latexes by miniemulsion polymerization and their pressure-sensitive adhesive applications, Macromolecules (2011) 2632-2642.

[25] U.G. Spizzirri, O.I. Parisi, F. Iemma, G. Cirillo, F. Puoci, M. Curcio, N. Picci, Antioxidant-polysaccharide conjugates for food application by eco-friendly grafting procedure, Carbohydr. Polym. 79 (2010) 333-340, https://doi.org/10.1016/j. carbpol.2009.08.010.

[26] A.S. Singha, A. Guleria, R.K. Rana, Ascorbic Acid = H 2 O 2 -initiated graft copolymerization of methyl methacrylate onto abelmoschus esculentus fiber: a kinetic approach, Int. J. Polym. Anal. Charact. 18 (2013) 1-14, https://doi.org/10.1080/ 1023666X.2012.723852.

[27] M. Kitagawa, Y. Tokiwa, Polymerization of vinyl sugar ester using ascorbic acid and hydrogen peroxide as a redox reagent, Carbohydr. Polym. 64 (2006) 218-223, https://doi.org/10.1016/j.carbpol.2005.11.029.

[28] J.C. Deutsch, Ascorbic acid oxidation by hydrogen peroxide, Anal. Biochem. 255 (1998) 1-7, https://doi.org/10.1006/abio.1997.2293.

[29] M. Li, E.S. Daniels, V. Dimonie, E. David Sudol, M.S. El-Aasser, Preparation of polyurethane/acrylic hybrid nanoparticles via a miniemulsion polymerization process, Macromolecules 38 (2005) 4183-4192, https://doi.org/10.1021/ $\mathrm{ma048141z.}$

[30] H. Xu, F. Qiu, Y. Wang, D. Yang, W. Wu, Z. Chen, J. Zhu, Preparation, mechanical properties of waterborne polyurethane and crosslinked polyurethane-acrylate composite, J. Appl. Polym. Sci. 124 (2012) 958-968, https://doi.org/10.1002/app. 35127.

[31] B.K. Kim, Y.M. Lee, Aqueous dispersion of polyurethanes containing ionic and non ionic hydrophilic segments, J. Appl. Polym. Sci. 54 (1994) 1809-1815, https://doi. org/10.1002/app.1994.070541204.

[32] Z. Wang, D. Gao, J. Yang, Y. Chen, Synthesis and characterization of UV-curable waterborne polyurethane-acrylate ionomers for coatings, J. Appl. Polym. Sci
73 (1999) 2869-2876, https://doi.org/10.1002/(SICI)1097-4628(19990929)73: 14<2869:AID-APP10 > 3.0.CO;2-S

[33] Y. Chen, Y.-L. Chen, Aqueous dispersions of polyurethane anionomers: effects of countercation, J. Appl. Polym. Sci. 46 (1992) 435-443, https://doi.org/10.1002/ app.1992.070460308.

[34] C.P. Chwang, C.L. Wang, Y.M. Kuo, S.N. Lee, A. Chao, D.Y. Chao, On the study of polyurethane Ionomer-Part I, Polym. Adv. Technol. 13 (2002) 285-292, https:// doi.org/10.1002/pat.187.

[35] R.J. Farn, Chemistry and Technology of Surfactants, Blackwell Publishing Ltd, Oxford UK, 2006https://doi.org/10.1002/9780470988596.

[36] Y.G. Park, Y.H. Lee, M.M. Rahman, C.C. Park, H. Do Kim, Preparation and properties of waterborne polyurethane/self-cross-linkable fluorinated acrylic copolymer hybrid emulsions using a solvent/emulsifier-free method, Colloid. Polym. Sci. 293 (2015) 1369-1382, https://doi.org/10.1007/s00396-015-3504-0.

[37] M. Sadeghi, M.A. Semsarzadeh, M. Barikani, B. Ghalei, Study on the morphology and gas permeation property of polyurethane membranes, J. Memb. Sci. 385-386 (2011) 76-85, https://doi.org/10.1016/j.memsci.2011.09.024.

[38] J.A. Jofre-Reche, V. García-Pacios, V. Costa, M. Colera, J.M. Martín-Martínez, Role of the interactions between carbonate groups on the phase separation and properties of waterborne polyurethane dispersions prepared with copolymers of polycarbonate diol, Prog. Org. Coatings88 (2015) 199-211, https://doi.org/10.1016/j. porgcoat.2015.06.029.

[39] M.A. Pérez-Limiñana, F. Arán-Aís, A.M. Torró-Palau, A.C. Orgilés-Barceló, J.M. Martín-Martínez, Characterization of waterborne polyurethane adhesives containing different amounts of ionic groups, Int. J. Adhes. Adhes. 25 (2005) 507-517, https://doi.org/10.1016/j.ijadhadh.2005.02.002.

[40] M. Zou, S. Wang, Z. Zhang, X. Ge, Preparation and characterization of polysiloxane-poly(butyl acrylate-styrene) composite latices and their film properties, Eur. Polym. J. 41 (2005) 2602-2613, https://doi.org/10.1016/j.eurpolymj.2005.05. 038.

[41] C. Wang, F. Chu, C. Graillat, A. Guyot, C. Gauthier, J.P. Chapel, Hybrid polymer latexes: acrylics-polyurethane from miniemulsion polymerization: properties of hybrid latexes versus blends, Polymer (Guildf)46 (2005) 1113-1124, https://doi.org/ 10.1016/j.polymer.2004.11.051.

[42] M. Shin, Y. Lee, M. Rahman, H. Kim, Synthesis and properties of waterborne $\mathrm{fl}$ uorinated polyurethane-acrylate using a solvent-/emulsi fi er-free method, Polymer (Guildf)54 (2013) 4873-4882, https://doi.org/10.1016/j.polymer.2013.07.005.

[43] M. Li, Z. Zheng, S. Liu, Y. Su, W. Wei, X. Wang, Synthesis and properties of poly(acrylates-co-urethane) adhesives for low surface energy materials, Int. J. Adhes. Adhes. 31 (2011) 565-570, https://doi.org/10.1016/j.ijadhadh.2011.05.006.

[44] Y.-S. Ryu, Y.-H. Lee, J.-S. Kim, C.-C. Park, H.-D. Kim, Preparation and properties of emulsifier-/solvent-free polyurethane-acrylic hybrid emulsions for binder materials: effect of the glycidyl methacrylate/acrylonitrile content, J. Appl. Polym. Sci. 134 (2017) https://doi.org/10.1002/app.44497, n/a-n/a.

[45] M.R. Rivera, A.A. Rodríguez-Hernández, N. Hernández, P. Castillo, E. Saldívar, L. Ríos, Controlled/living free radical copolymerization of styrene and butyl acrylate in bulk and emulsion with industrial monomers. influence of monomer addition on polymer properties, Ind. Eng. Chem. Res. 44 (2005) 2792-2801, https://doi.org/ $10.1021 / \mathrm{ie} 040160+$ 